\title{
A Naval Analysis of Microstrip Antenna Array using Various Elements for ISM-Band

\author{
Chaitanya Bethala, K. Manjunathchari
}

\begin{abstract}
Right now, point is to contrast single fix receiving patch and 1x2 exhibit and $1 \times 4$ radio patch on FR4. The emphasis will be on upgrading the elements of fix reception apparatus additionally kept up a high increase in the ISM band (2.3 $\mathrm{GHz}$ to $2.6 \mathrm{GHz}$ ) at focus recurrence $2.45 \mathrm{GHz}$. Various parameters of reception apparatus like VSWR, return loss, increase gain and radiation design are reproduced utilizing Ansoft HFSS programming v13. Microstrip patch radio wire in remote correspondence is picking up significance as a most impressive mechanical pattern. Its enormous potential guarantees huge change in close to term eventual fate of remote application fields. The current innovative pattern has concentrated on microstrip patch radio wire. Single microstrip patch reception apparatus has a few favorable circumstances (ease, lightweight, conformal and low profile), however, it has little detriments too-like low addition, low productivity, low directivity, and thin data transfer capacity. These weaknesses can be overwhelmed by the execution of many fix reception apparatuses in a cluster design. Here term exhibit represents geometrical and electrical courses of action of fix components. As we increment the number of patch components to frame a cluster, improvement in execution is watched. Right now, for $1 \times 1$, $1 \times 2,1 \times 4$ clusters have been investigated and thought about. It has been inferred that the $1 \times 4$ patch cluster shows a preferable outcome over a single patch.
\end{abstract}

Keyword: Micro-patch, array elements, $1 \times 2$ and $1 \times 4$ clusters, gain, return loss.

\section{INTRODUCTION}

ISM implies Industrial, Scientific and Medical recurrence band. This is a band of radio and microwave frequencies grouped around $2.4 \mathrm{GHz}$, saved and assigned for modern, logical and clinical hardware that utilization RF. Modern gear like MRI machines, testing hardware, and some radio telescopes utilize this ISM band of frequencies. Simple consumer equipment, for example, microwaves, carport entryway framework, codeless telephone, remote switch and remote mouse are likewise intended to run at frequencies around $2.4 \mathrm{GHz}$.

Manuscript received on March 15, 2020

Revised Manuscript received on March 24, 2020.

Manuscript published on March 30, 2020.

* Correspondence Author

Chaitanya Bethala*, Assistant Professor, Department of Electrical, Electronics \& Communication Engineering, GITAM (Deemed to be University). E-mail: cbethala@gitam.edu

K. Manjunathchari, Professor, Department of Electrical, Electronics \& Communication Engineering, GITAM (Deemed to be University). E-mail: mkamsali@gitam.edu

(C) The Authors. Published by Blue Eyes Intelligence Engineering and Sciences Publication (BEIESP). This is an open access article under the CC BY-NC-ND license (http://creativecommons.org/licenses/by-nc-nd/4.0/)
Most media transmission equipment work at a much lower recurrence than $2.4 \mathrm{GHz}$. Having different gadgets work at just a specific recurrence run, right now, decreases obstruction with the media transmission frequencies. This implies utilizing a remote switch and a mobile phone at the time will have no obstruction with one another.

Comprising of a dielectric substrate sandwiched in the middle of a ground plane and a fix. The idea of the Microstrip reception apparatus was first proposed in 1953, twenty years before the viable radio wires were delivered [12]. Since the principal down to earth reception apparatuses were created in the mid-1970s. A portion of the primary edges of the microstrip reception apparatuses is that it has lesser manufacture cost, its little weight, less volume, and low profile arrangements that it very well may be made conformal, it tends to be effectively be mounted on rockets, rockets, and satellites without significant alterations with the ever-expanding requirement for versatile correspondence and the rise of numerous frameworks, it is essential to plan broadband radio wires to cover a wide recurrence extend [35]. The plan of a productive wide band little size radio wire, for ongoing remote applications, is a troublesome errand. Microstrippatch radio wires have discovered broad application in remote correspondence framework attributable to their preferences, for example, low profile, similarity; ease creation and simplicity of combination with feed systems [4-6]. Be that as it may, these receiving wires are commonly manufactured on thicker substrates. The addition of a solitary fix radio wire is additionally expanded by expanding the no of cluster components. Each cluster component improves the increase of a radio wire. The proposed single fix, $1 \times 2$ patch and $1 \times 4$ [8-10] patch are planned and look at their changed parameter. It has been reasoned that a $1 \times 4$ exhibit shows preferred execution over a single fix receiving wire. Different exhibits improve the addition of a radio wire just as the data transmission of the receiving wire.

\section{DESIGN ANALYSIS}

There are a few sorts of investigation model accessible for microstrippatch radio wire transmission mechanism, cavity mechanism, and full wave mechanism (which incorporate essential fundamental conditions/minuscule technique) in which transmission mechanism is most simple, direct technique and having great physical perceptive [11-13].

\subsection{Transmission mechanism}

In the communicationmethod, the microstrippatch antenna having the edges at the ends of the antenna, it has L and $\mathrm{W}$. These having different substrate material and different dielectric values in the applicable medium. 


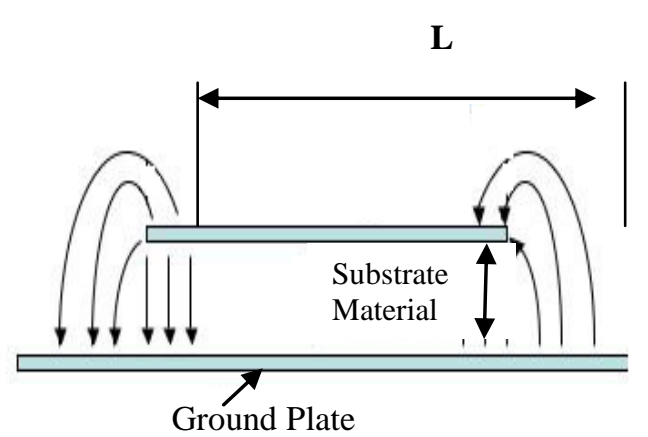

Figure 1: Field Lines

Along these lines, most by far of the field lines exist in the substrate material and some parts of specific lines noticeable all around which is showed up in figure 1 . Subsequently, this transmission mechanism can't support the unmodified Transverse electromagnetic (TEM) technique for transmission, in light of the fact that the stage paces would be particularly recognizable substrate material. Instead of the overwhelming strategy for spread, it would be the quasi-TEM. An amazing dielectric consistent $\left(\varepsilon_{\text {reff }}\right)$ must be accomplished for the flanking and the wave spread in the line. The approximation of $\varepsilon_{\text {reff }}$ is not actually $\varepsilon_{\mathrm{r}}$ in light of the fact that the flanking fields at the edge of the patch are not limited in the dielectric substrate material however then again, are transmitted perceptible all around as showed up in Figure above.

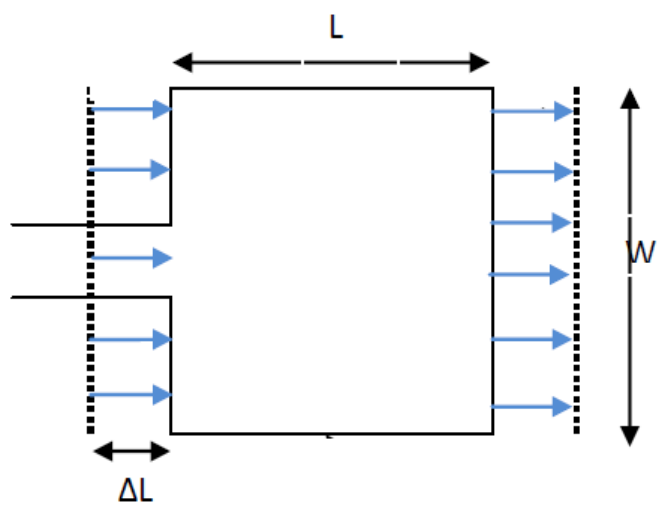

Figure 2: Radiating edges from top view

The patch length should be not exactly $\lambda / 2$ for working in essential TM10 mode, everywhere $\lambda$ be the frequency in the dielectric medium which is corresponding to the proportion of frequency in free space to $\sqrt{ } \varepsilon_{\text {reff. }}$ The TM10 model advises that the field oscillates one $\lambda / 2$, all along the length, and there is no variation along the width. The figure 2 show the microstrip patch reception apparatus which is says that to by two spaces isolated by length " $\mathrm{L}$ " and ends are open at the edges of the antenna. The current is least because of edges of the antenna, yet voltage is most extreme along the ' $\mathrm{W}$ ' of the patch. The field is produced at the ends having distinctive segments regarding the bottom plane.

The design Specification of the antennas is:

$\mathrm{W}=$ Patch width $==\frac{C}{2 f_{0} \sqrt{\frac{\varepsilon_{r+1}}{2}}}$

Where $\mathrm{f}_{0}$ is the antenna working frequency=L-Band and $\mathrm{C}$ acting as a velocity of light.

$$
\varepsilon_{r}=\frac{\varepsilon_{r}+1}{2}+\frac{\varepsilon_{r}-1}{2}\left\{1+12 \frac{h}{w}\right\}^{-\frac{1}{2}}
$$

$$
\begin{gathered}
\mathrm{W}_{\mathrm{g}}=2 * \mathrm{w} \\
f_{1}=\frac{6 h}{2} \\
W_{f}=\frac{f_{1}}{2} \\
f_{1}=10^{-4}\left(0.001699 * \varepsilon_{r}^{7}+0.13761 * \varepsilon_{r}^{6}-6.1783 * \varepsilon_{r}^{5}\right. \\
\left.+93187 * \varepsilon_{r}^{4}-682.69 * \varepsilon_{r}^{3}\right)
\end{gathered}
$$$$
\mathrm{L}_{\mathrm{g}}=2 * \mathrm{~L}
$$$$
L=L_{e f f-} 2 \Delta L
$$

Table 1: Antenna Dimension

\begin{tabular}{|l|l|}
\hline Parameters & Values $(\mathrm{mm})$ \\
\hline W & 38 \\
\hline L & 29 \\
\hline Substrate thickness & 1.6 \\
\hline Substrate & FR4 \\
\hline
\end{tabular}

\subsection{ANTENNA FEEDING METHODS}

In micro strip patch antenna having four major types of feeding mechanisms are available, like coaxial coupling, aperture feeding, microstrip line coupling and proximity coupling. The paper present the microstrip line feeding method used.

\section{ANTENNA STRUCTURAL DESIGN AND SIMULATE RESULTS}

\subsection{Single Rectangular Patch Antenna}

The conservative rectangular microstrippatch of $38 * 29$ millimeter ispositionedabovethe dielectric substrate material of $50 * 50 * 1.6$ cube mm have dielectric constant of fixed value is 4.4. Projectedstructure is shown in figure 3. In this paper focus on strip line couplingmethod is used. For proper impedance toning between patch and strip line of $3 \mathrm{~mm}$ width, feed line of $13.29 \mathrm{~mm}$ is used.

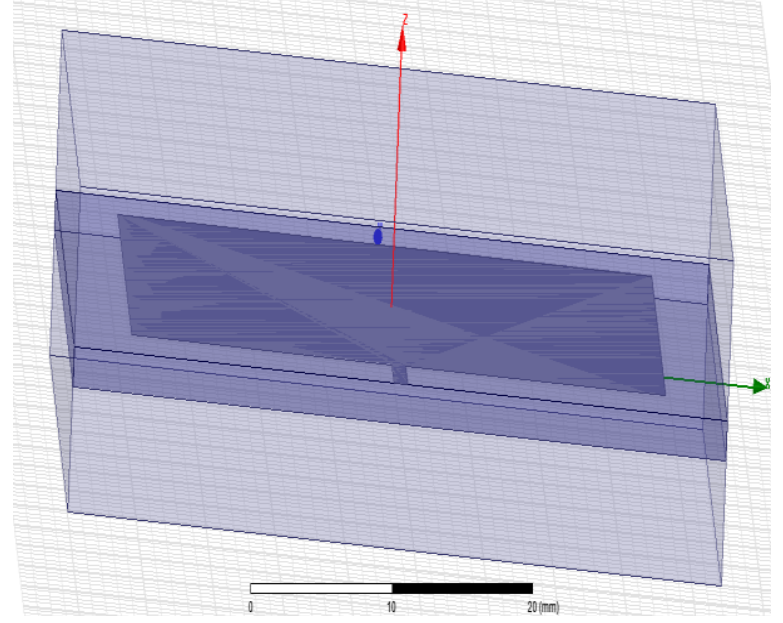

Figure 3: Geometry structure of single Rectangular Patch antenna

Blue Eyes Intelligence Engineering \& Sciences Publication 
The models results obtain by a single Microstrippatch are certain in Figure 4. It is noticed that conventional patch type antenna having $-17.27 \mathrm{~dB}$ return loss and resonant at 2.33 $\mathrm{GHz}$ frequency. Calculated Impedance of Bandwidth4.5\%.

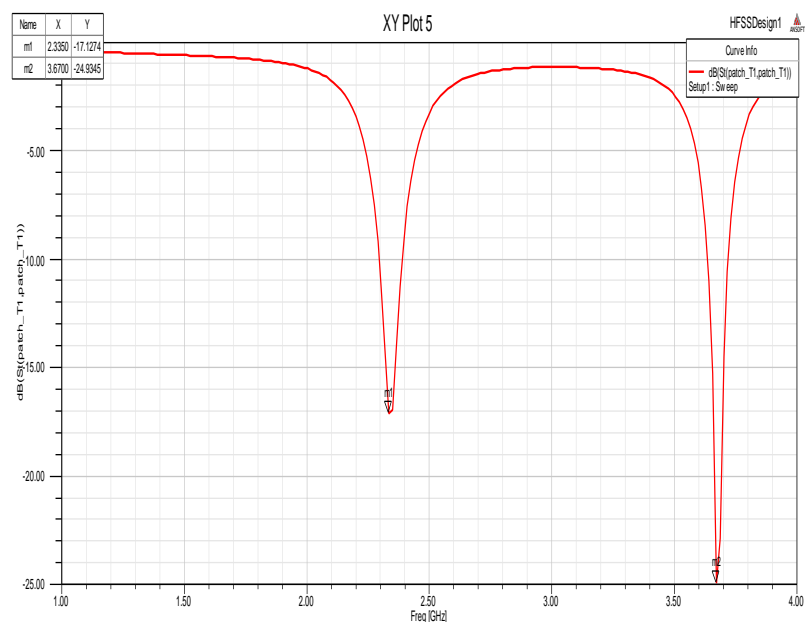

Figure 4: S11conjunction frequency plot
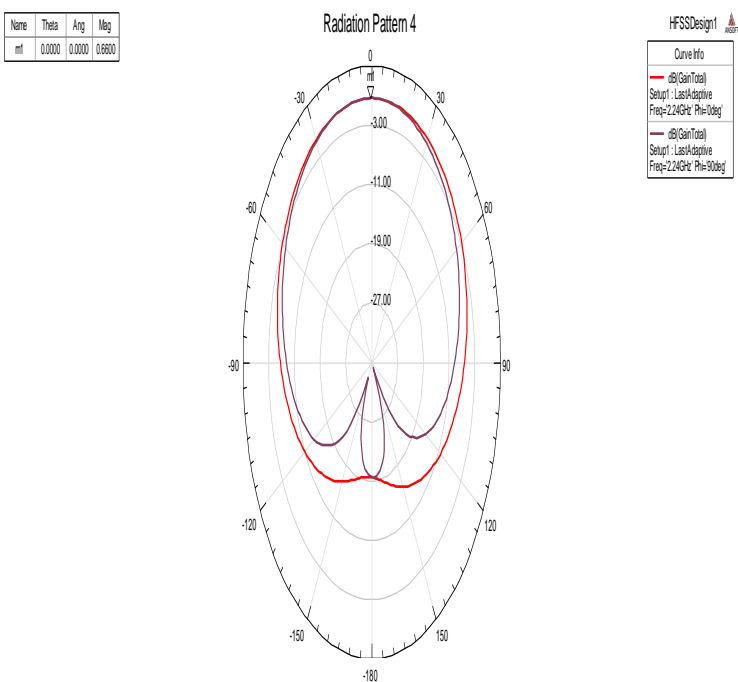

Figure5: Gain conjunction Angle

\section{B. Two Component Patch Antenna}

For increasing the gain, two quadrangular slots of $38 * 29 \mathrm{~mm}$ are used in the conventional patch. Figure 6display the geometrical construction of two element patch antenna.

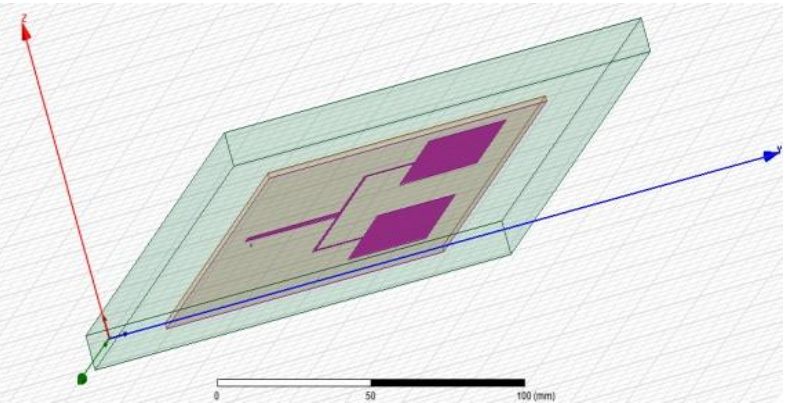

Figure 6: Geometrical construction of two element Patch antenna

The software simulated S11return loss conjunctionto the frequency is displays in figure7. Here observing that resonant frequency is increased and bandwidth is increased. The antenna is having $4.08 \%$ bandwidth at $2.45 \mathrm{GHz}$ resonant frequency.

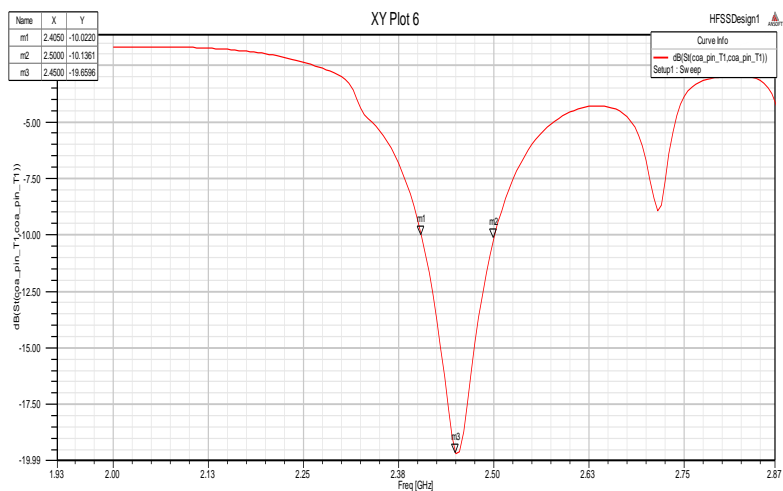

Figure 8: S11conjunction frequency plot
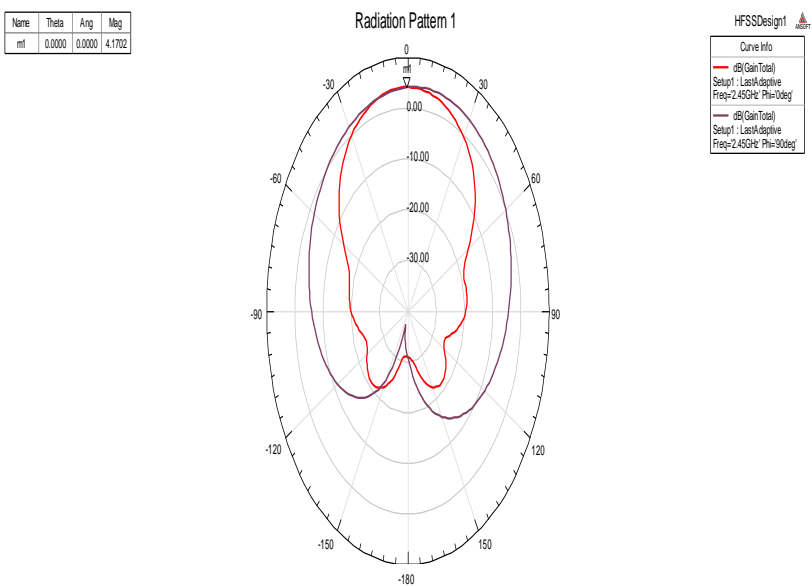

Figure 9: Gain conjunction Angle

\section{Four Element Patch Antenna}

For enhancing the gain and four element arrays are used. Figure 10 displays the geometrical construction of four elementpatch antenna.

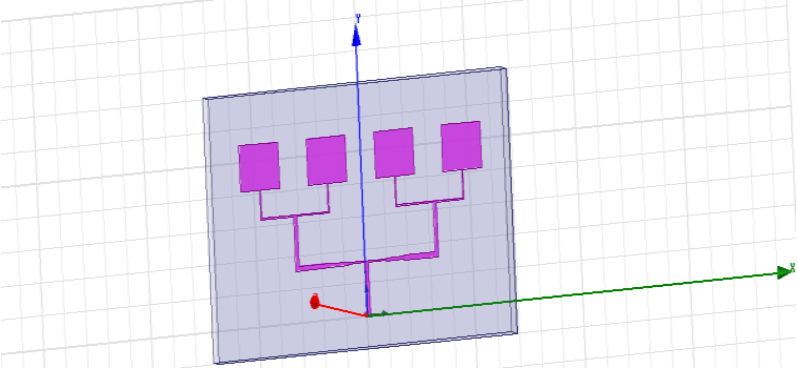

Figure 10: Geometrical construction of four element Patch antenna

In this, the S11 conjunction to the frequency, which is available in figure 11, it is noticed that theantenna is resonated at $2.48 \mathrm{GHz}$ frequency. The calculated impedance bandwidth is $4.43 \%$. 


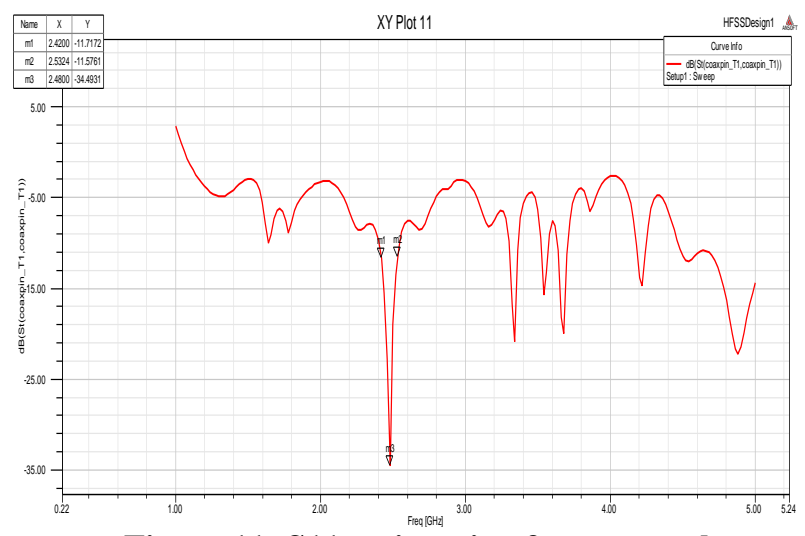

Figure 11: S11conjunction frequency plot

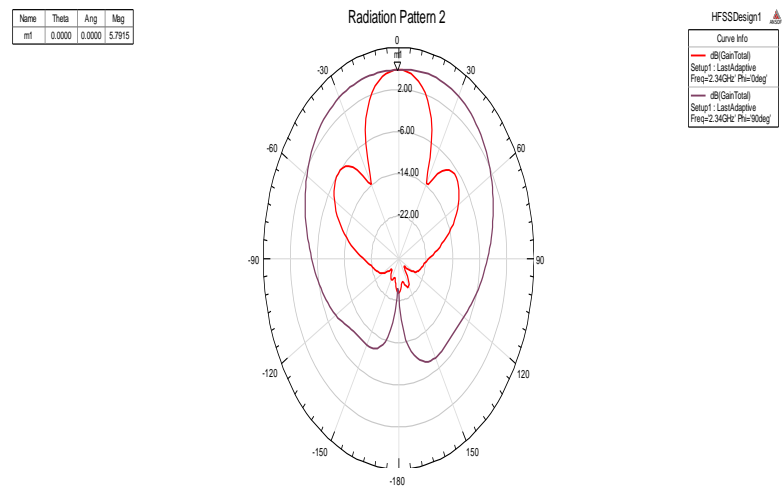

Figure 12: Gainconjunction Angle

\section{Comparative Analysis of Gain:}

By measuring the antenna performance gain is also an important asset of the antenna. The below table displays the comparative analysis of the antenna parameter.

Table2: Comparativeanalysis of simulated results of return loss parameter

\begin{tabular}{|l|l|l|l|l|}
\hline $\begin{array}{l}\text { Arrange } \\
\text { ment }\end{array}$ & $\begin{array}{l}\text { Band } \\
\text { width } \\
(\%)\end{array}$ & $\begin{array}{l}\text { Resona } \\
\text { nt } \\
\text { frequen } \\
\text { cy } \\
(\mathrm{GHz})\end{array}$ & $\begin{array}{l}\text { Gain in } \\
\mathrm{dB}\end{array}$ & $\begin{array}{l}\text { Return } \\
\text { loss (dB) }\end{array}$ \\
\hline $\begin{array}{l}\text { Single } \\
\text { patch } \\
\text { antenna }\end{array}$ & 4.5 & 2.335 & 0.66 & -17.274 \\
\hline $\begin{array}{l}\text { 1x2 patch } \\
\text { array } \\
\text { antenna }\end{array}$ & 4.08 & 2.45 & 4.17 & -19.65 \\
\hline $\begin{array}{l}\text { 1x4 patch } \\
\text { antenna }\end{array}$ & 4.43 & 2.48 & 5.79 & -34.49 \\
\hline
\end{tabular}

\section{E. Fabricated Antennas}

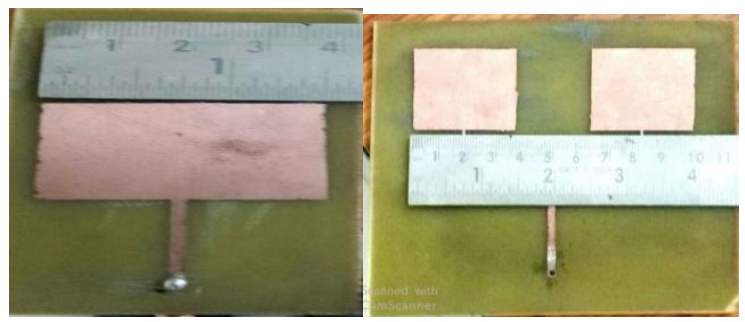

Figure 13: Single patch\&two element array

Retrieval Number: F9378038620/2020@BEIESP

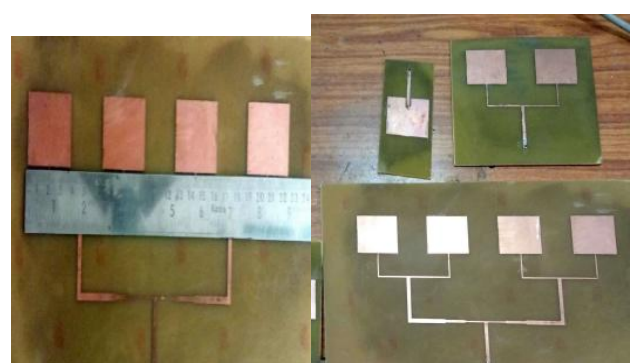

Figure 14: Four element arrays

Table3: Comparison of measured results.

\begin{tabular}{|l|l|l|l|l|}
\hline $\begin{array}{l}\text { Arrangem } \\
\text { ent }\end{array}$ & $\begin{array}{l}\text { Bandw } \\
\text { idth } \\
(\%)\end{array}$ & $\begin{array}{l}\text { Reason } \\
\text { ant frequ } \\
\text { ency } \\
(\mathrm{GHz})\end{array}$ & $\begin{array}{l}\text { Gain } \\
\text { in dB }\end{array}$ & $\begin{array}{l}\text { Return } \\
\text { loss (dB) }\end{array}$ \\
\hline $\begin{array}{l}\text { Single } \\
\text { patch } \\
\text { antenna }\end{array}$ & 4.5 & 2.3 & 0.41 & -17.274 \\
\hline $\begin{array}{l}\text { 1x2 patch } \\
\text { array } \\
\text { antenna }\end{array}$ & 4.08 & 2.45 & 4.1 & -19.65 \\
\hline $\begin{array}{l}\text { 1x4 patch } \\
\text { antenna }\end{array}$ & 4.43 & 2.45 & 7.23 & -34.49 \\
\hline
\end{tabular}

\section{CONCLUSION}

Right now, is contemplated, planned and reproduced three parts of a micro strip patch transmitting and receiving wire, The first is the rectangular patch, second is a twocomponent exhibit and the third is four-component clusters by utilizing High-frequency structure test system. There is a critical upgrade in the increase in four-component exhibits in contrast with two-component and single Rectangular fix reception apparatus.

\section{REFERENCES}

1. Christodoulou C G, Youssef Tawk, Steven A. Lane, and Scott R.Erwin, "Reconfigurable Antennas for Wireless and SpaceApplication" Proceedings of the IEEE Vol. 100, No. 7, July 2012.

2. Joseph Constantine, Youssef Tawk, Silvio E. Barbin, and Christos G.Christodoulou,"Reconfigurable Antennas: Design and Applications"Proceedings of the IEEE | Vol. 103, No. 3, March 2015.

3. Antennas in modern wireless Communication and sensing system"

4. Y. Jay Guo, Pei-Yuan Qin and Trevor S. Bird, "ReconfigurableAntennas for Wireless Communications" 7th European Conferenceon Antennas and Propagation (EUCAP 2013), 8-12 April, 2013.

5. Songnan Yang, Chunna Zhang, Helen K Plan, Aly E Fathy andVijay K Nair "Frequency Reconfigurable Antenna for MultiradioWireless Platform”- IEEE Microwave Magazine Vol. 10 Issue 1,February 2009.

6. Yahya S. H. Khraisat and Ahmad H. N. Qubaia"Reconfigurable Antenna Design" PIERS Proceedings, Prague,Czech Republic, July 6 - 9, 2015.

7. BaharehBadamchi, Java

Nourinia, ChangizGhobadi,ArashValizadeShahmirzadi, Design of compact reconfigurable ultra-wideband slotantenna with switchable single/dual bandnotch functions"IETMicrowave. Antennas Propag, 2014, Vol. 8, Iss. 8, pp. 541-548.

8. A. Mansoul,H. Kimouche "A Simple FrequencyReconfigurable Microstrip Patch Antenna For WirelessCommunication" The 8th International Workshop on Systems, SignalProcessing and their Applications 2013: Special Sessions. 12-15 May2013, Algiers, Algeria.
Published By:

Blue Eyes Intelligence Engineering \& Sciences Publication 
9. N. Ramli, M. T. Ali, A. L. Yusof1, S. Muhamud - Kayat, andA. A. A. Aziz "PINDiode Switches for Frequency-Reconfigurable Stacked PatchMicrostrip Array Antenna using Aperture-Coupled Technique" 2013Asia-Pacific Microwave Conference Proceedings 5-8 Nov 2013,Seoul, South Korea.

10. M. F. Ismail, M. K. A.Rahim, H. A. Majid "The Investigationof PIN Diode Switch on Reconfigurable Antenna"2011 IEEEInternational RF and Microwave Conference (RFM 2011), 12 -14December 2011, Seremban, Malaysia.Propagation Letters 5 (2006): 402-405.

11. Xiaofan Yang, Yao Chen, Longfang Ye, Manxi Wang, Min Yu,QingHuo Liu "Frequency Reconfigurable Circular Patch Antenna using PIN Diodes" IEEE International Conference on Microwaveand Millimeter Wave Technology, 5-8 June 2016, Beijing China.

12. Ahmed Khidre, Fan Yang, and Atef Z. Elsherbeni"A PatchAntenna with a Varactor-Loaded Slot for Reconfigurable DualBandOperation"IEEE Transactions on Antennas and Propagation,Vol.63, No. 2, February 2015.

13. L. N. Pringle, et al., "A Reconfigurable Aperture AntennaBased on Switched Links between Electrically Small MetallicPatches," IEEE Transactions on Antennas and Propagation, AP-52, 6,June 2004, pp. 1434-1445.

\section{AUTHORS PROFILE}

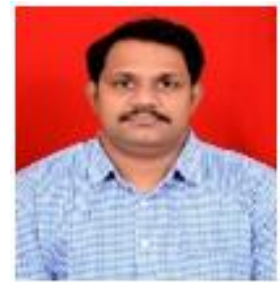

Mr. Chaitanya Bethala, Assistant Professor, Department of Electrical, Electronics \& CommunicationEngineering, GITAM School of Technology, Hyderabad Campus, completed in $M$. Tech (Microwave Engineering). Presently, he is working as Assistant professor in Electrical and Electronics Engineering Department, School University) Hyderabad, Telangana.

of Technology, GITAM (Deemed to be

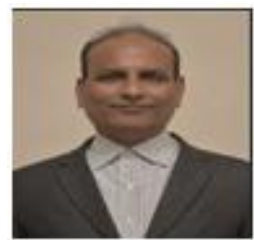

Dr. K. Manjunathachari received his $\mathrm{Ph}$. D from JNT University, Kakinada. He is having 18 years teaching experience and 3 years of Industry experience. At present Dr.K. Manjunatha Chari is working asProfessor \& HOD, Department of Electrical, Electronics \& Communication Engineering, School of Technology, GITAM (Deemed to be University), Hyderabad,Telangana. He has published more than 50 research articles in reputed journals. 